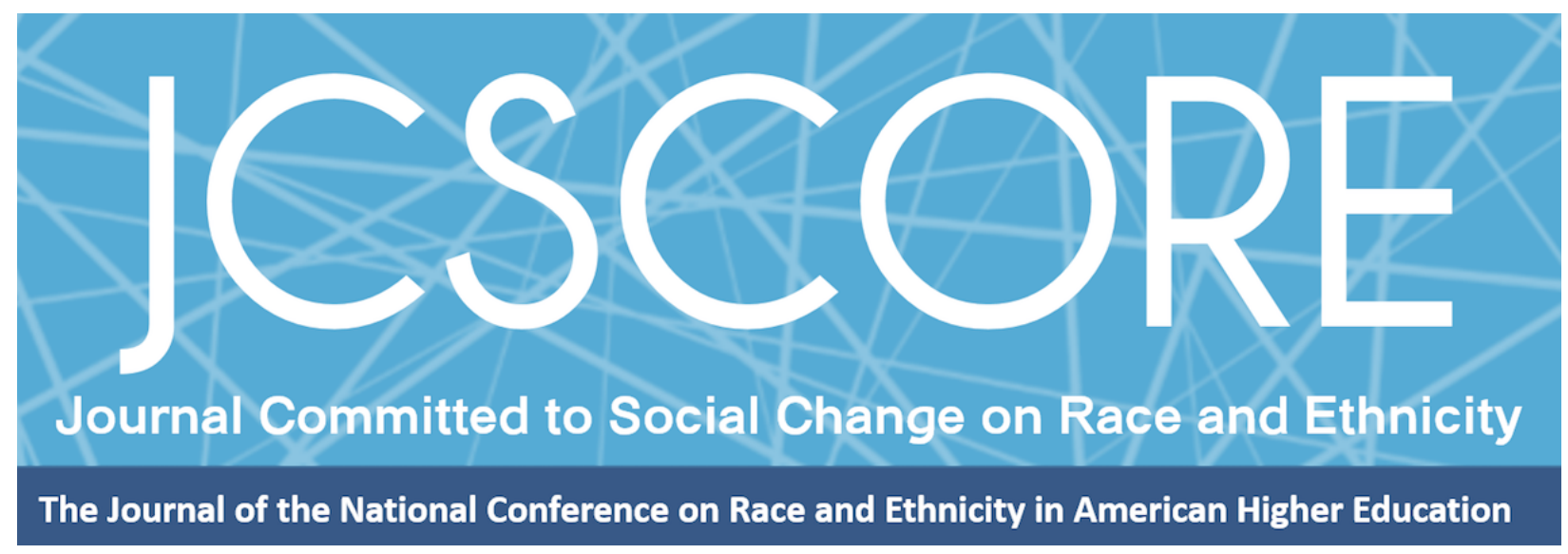

\title{
“FROM WHITE DEAF PEOPLE'S ADVERSITY TO BLACK DEAF GAIN": A PROPOSAL FOR A NEW LENS OF BLACK DEAF EDUCATIONAL HISTORY
}

\author{
Rezenet Tsegay Moges \\ California State University, Long Beach
}

Journal Committed to Social Change on Race and Ethnicity

Volume 6, Issue 1 | 2020

Copyright and Open Access

(C) 2020 Rezenet Tsegay Moges

\section{(c) (i) (2) (2)}

This work is licensed under a Creative Commons Attribution-NonCommercial-ShareAlike 4.0 International License. Permission of the authors is required for distribution and for all derivative works, including compilations and translations. Quoting small sections of text is allowed as long as there is appropriate attribution and the article is used for non-commercial purposes.

The Journal Committed to Social Change on Race and Ethnicity (ISSN 2642-2387) is published by the National Conference on Race and Ethnicity (NCORE), a production of the University of Oklahoma, in partnership with the University of Oklahoma Libraries. 


\title{
"From White Deaf People's Adversity to Black Deaf Gain": A Proposal for a New Lens of Black Deaf Educational History
}

Rezenet Tsegay Moges

California State University, Long Beach

\begin{abstract}
This paper re-visits Bauman and Murray's (2014) "Deaf Gain," using the perspectives of Black Deaf history. Due to the enforcement of the Oral policy in U.S. educational system during 1890s through 1960s, the language transmission of American Sign Language (ASL) for many generations of White Deaf people were fractured (Gannon, 1981). During the segregation, approximately $81.25 \%$ of the Black Deaf schools maintained their signed education, which ironically provided better education than the White-only schools. Consequently, the language variation of Black Deaf people in the South, called as "Black ASL" (McCaskill et al., 2011), flourished due to the historical adversity of White Deaf experience. Thus, the sustainability of Black ASL empowered this ethnic group of American Deaf community, which I am re-framing to what I call "Black Deaf Gain" and presenting a different objective of the ontology of Black Deaf experience.
\end{abstract}

From the 1890 s to the 1960 s, the United States educational system adopted primarily oralism, forcing deaf children to learn speaking and lip-reading and banning the use of their hands (Lane 2013/1984). On the contrary, manualism, a form of education taught in the visual-manual modality that is sign language, had faltered during this period. As a result, the language transmission of American Sign Language (ASL) was fractured for many generations of white Deaf people (Gannon, 1981). Racial segregation, particularly in the Southern states, meant that the majority of Black Deaf schools continued to use the manual method, thus ensuring signed language transmission and access to information from one generation to the next (Baynton, 
Journal Committed to Social Change on Race and Ethnicity | Volume 6, Issue 1 | 2020

1996). As a Black Deaf scholar, myself, I am no longer interested in reading the repetitive master-narrative from a white perspective, which lacks a Black Deaf centralized history. This paper provides a historical interpretation with a critical lens and draws on counter-narratives by re-visiting the notion of "Deaf Gain" (Bauman \& Murray, 2009).

The concept of Deaf Gain pushes for a paradigm shift from the devaluating label of "hearing loss," which was established by the ideological "normalcy" of white ablebodied/all-sensorial Americans during the early $20^{\text {th }}$ century (Bauman \& Murray, 2009). Instead of focusing on the "bio-cultural diversity" ${ }^{1}$ of the general Deaf population, I focus specifically on Black Deaf people. My argument is that the coercion of a white ablebodied homogeneity and the ideology of reforming neglected Black Deaf bodies became, in turn, a form of Deaf empowerment—an unintentional positive consequence for Black Deaf Americans. Consequently, because of manualism, the identity of Black Deaf people thrived. Despite their underfunded segregated school system and limited resources, the language variation of Black Deaf people in the South, which is now called "Black ASL" (Aramburo, 1989; McCaskill et al., 2011), flourished due to the historical adversity that white Deaf people had experienced. Thus, the sustainability of Black ASL empowered this ethnic group of the American Deaf community, which I am proposing to call "Black Deaf Gain" and to present a different objective of the ontology of the Black Deaf experience. Black Deaf Gain is a movement of a new way of thinking and re-evaluating a master narrative of historical (and on-going) oppressions of racism with antiblackness (Dumas \& ross, 2016), audism (Humphries, 1977) and linguicism

${ }^{1}$ This refers to biological diversity with linguistic and cultural diversity (Bauman \& Murray, 2009). 
Journal Committed to Social Change on Race and Ethnicity | Volume 6, Issue 1 | 2020

(Skutnabb-Kangas, 1988). This concept will be further explored in a framework with the intersectional lens of Black Deaf lives and experiences.

\section{Reexamining Theoretical Framework(s)}

This paper incorporates critical race theory (CRT), which emerged from "a collection of activists and scholars interested in studying and transforming the relationship among race, racism, and power" (Delgado \& Stefancic, 2001, p. 2). While CRT discusses systemic racism in general (Solórzano, 1997), Black Critical Theory (BlackCrit) draws the focus on the Black experience, specifically antiblackness, which is a social construction that is seen "as an antagonism, in which the Black is a despised thing-in-itself" (Dumas \& ross, 2016, p. 416). In addition, since this study concentrates mainly on Black Deaf people, antiblackness is weaved throughout the frameworks used in this paper. However, CRT and BlackCrit leaves out the Deaf experiences of audism and linguicism, which are incorporated in the next framework.

A Deaf Latina scholar, Dr. Carla García-Fernández, introduced "Deaf Latin[x] Critical Theory" (2014; in this volume), in which a new theoretical framework merges CRT and Latinx Deaf epistemology. Her theory complements CRT by focusing on minoritized identities who deal with race/racism and linguicism, which are both acts of oppression of racial and linguistic differences respectively. Her framework is based on "LatCrit" theory, which Solórzano and Yosso (2002) moved away from the Black and white people binary established in the early work of critical theory by concentrating on racism and Latina/o racial, ethnic, and cultural experiences, such as immigration, bilingualism, and colorism. For this case on Black Deaf history and to incorporate general Deaf experiences of oppression, I add to García-Fernández's theory with 
Journal Committed to Social Change on Race and Ethnicity | Volume 6, Issue 1 | 2020

audism which is the belief that hearing people are superior; thus, resulting in the marginalization of Deaf bodies (Humphries, 1977). This addition is to recognize Black

Deaf people's intersectional experiences of different oppressions in addition to systematic racism and linguicism. Deaf LatCrit is composed of four tenets: 1) intersectionality concentrating on two or more oppressed identities, which will incorporate racism and linguicism and diverge from a singular monolithic experience of any Deaf person, 2) ideologies highlighting linguistic ideologies being impacted from Eurocentric Deaf or speaking values, 3) consciousness raising critical perspectives and recognizing the values of words or a language in general and 4) storytelling giving spaces to listening counter-narratives about their experiences and sharing their racial epistemologies (García-Fernández, 2014).

Importantly, Deaf LatCrit overwrites the Eurocentric version of "Deaf Critical Theory" (Gertz, 2003), which erroneously focuses on only audism and results in practicing "intersectional erasure" (Abes \& Wallace, 2018, p. 547). The white-focused "Deaf Critical Theory" resulted in erasing Deaf People of Color (DPOC) and their intersectional identities and dismissed any racism inside and outside of Deaf communities. Thus, in this paper, the pushback against the whitewashing of Deaf experiences adopts Deaf LatCrit as a part of "pedagogies of resistance" (Ali \& Buenavista, 2018, p. 20), a critical education, identifying a variety of unjust oppressors, and strategizing of how to disempower the oppressors.

de Clerck (2010) reminds us that, "Further meta-theorizing can contribute significantly to the development of [a] critical project" (p. 436). This current paper fuses both deaf ontology and CRT, as already structured in Deaf LatCrit theory. It is important 
Journal Committed to Social Change on Race and Ethnicity | Volume 6, Issue 1 | 2020

to use the appropriate analyses from POC scholarship (Collins, 1986). Deaf ontology (Kusters et al., 2017) gathers the contributions to academia on deaf $^{2}$ people from insider observations; that is, from people who share similar identities to the research group, ensuring an ethical approach and benefiting from personal insights with subjectivity from these shared identities. These authors call for further research by Deaf scholars. Moreover, in my case, writing as a Deaf African American scholar, we bring our genuine affiliation of the research topic, which reflects our identities, and present an ontological methodology from the Black Deaf perspective. Maintaining the deafontological approach to use the Deaf LatCrit theory initialized by García-Fernández (who is also racially identified with her study group), this paper draws on other Deaf and/or signing Black scholars' historical documents. Since we focus specifically on a marginalized group, it is important to define the focal community of Black Deaf Americans, whose historical education is emphasized in this literature review.

Finally, in the article "From Hearing Loss to Deaf Gain," Bauman and Murray (2009) reframe Deaf scholarship to focus on the positive contribution of Deaf bodies to society, rather than dwelling on the pathology of absent sensorial ability. The scholars categorize the general deaf population as an addition to bio-cultural diversity (Bauman \& Murray, 2014), especially Black Deaf people, who count as a bio-diverse group. Deaf Gain is used as a key point of aligning the existence of the benefits of being Deaf and, in this case, Black. In ASL, GAIN is signed as ADVANTAGE/BENEFIT, signifying a celebration for being a Black Deaf person, which gained both of their identity formation and privileges through their educational and linguistic experience/history.

${ }^{2}$ Capitalized and non-capitalized letter of "Deaf" or "deaf" represents all ranges of those who are or are not culturally or politically-identified people respectively. 
Journal Committed to Social Change on Race and Ethnicity | Volume 6, Issue 1 | 2020

However, this added dimension specifically does not state that oppression does not exist, but entirely the opposite. By any means, POC perspectives "intersect with the experience-with-deafness dimension to create an emergent complex Deaf identity" (Parasnis, 2012, p. 69). Thus, this paper uses an ontological framework for a greater understanding of two things via a literature review: first, how this minority group was empowered by historical phenomena; and second, what it meant to be Black and Deaf in terms of the history shaping our language, culture, and identities. As Anzaldúa reminds us as POC scholars, "[b]y bringing in our own approaches and methodologies, we transform that theorizing space" (1990, p. xxv).

\section{Structure of this Critical Literature Review}

While this paper employs the framework of Deaf-LatCrit theory according to its four tenets, without any mistake or negligence, I do acknowledge the salient racial difference between Black and Latinx people. Nevertheless, I consider Deaf LatCrit to be a steppingstone for developing a critical concept and perspective about Black Deaf people/history through analyzing the shared multiple oppressions of antiblackness, systematic racism, linguicism, and audism. Historically, McCaskill's (2005) dissertation is considered one of the earliest works that uses a CRT framework on a Black Deaf study, exploring the narrative inquiries of 14 participants who were former students, teachers, and administrators from three desegregated Deaf schools. A decade later, a theoretical framework for a cohort of Black Deaf college graduates was developed (Stapleton, 2014; Stapleton \& Croom, 2017), although this was still a product of Gertz's (2003) Deaf Critical theory. These CRT studies on Black Deaf people resulted in an increase in Black Deaf scholarship. Maintaining and respecting the canonical work of 
Journal Committed to Social Change on Race and Ethnicity | Volume 6, Issue 1 | 2020

CRT scholars, this paper continues directly from the CRT framework without backsliding into Eurocentric Deaf Critical theory. After re-framing the history of education with Black Deaf Gain and the values imposed on Black Deaf people, Deaf LatCrit may be seen as an appropriate framework for other DPOC groups. Nonetheless, a universal framework for DPOC remains a work in progress.

The structure for evaluating a collection of published historical documentation and historians' work that focus specifically on Black Deaf history is composed along the four tenets of the Deaf-LatCrit framework to perform a critical literature review and historical interpretation. The four tenets framing this paper begin with intersectionality, ideologies, consciousness, and then closes with counter-narrative, which is the main point of CRT. Borrowing from the Deaf-LatCrit framework, each tenet shapes and reviews different categories of the literature observation based on a collection of historical or linguistic research. First, for intersectionality, the multiple identities and oppressions are defined. Second, ideologies will focus on the historical dichotomy of educational and communicative methods, representing the different cultural and racial values implemented by the white Deaf educational policy. Third, in the section on consciousness, I will highlight linguistic research focusing on language variation finally being formally termed as "Black ASL," introducing a linguistic anthropological perspective. Fourth, the critical race methodology (Solórzano \& Yosso, 2002) is adopted to induce a shift from "traditional research paradigms, texts, and theories" (p. 26) framing the history or stories, challenging readers to perceive the history of Black Deaf education and people from another perspective-specifically the Black perspective. To achieve this, I present counter-narratives with concrete evidence from several survivors' 
Journal Committed to Social Change on Race and Ethnicity | Volume 6, Issue 1 | 2020

life stories of their schooldays, including signed anecdotes from Black Deaf narrators (two female and one male) from "Black ASL" research, a video documentary, and several printed life experiences. After following each tenet, I assess and identify different forms of Black Deaf Gain from each analysis in the summaries.

\section{Intersectionality}

After introducing CRT in the legal field, intersectionality (Crenshaw, 1989, 1991) provided a platform to consider and accommodate those people with multiple identities who experience various intersections of differential oppressions simultaneously. The term resulted from focusing on the identities of Black women experiencing (unlawful) discrimination of racism and sexism, which consequently marginalizes other oppressed identities associated with unfair treatment (Crenshaw, 1989, 1991). Thus, for this paper, I define the intersectionality of Black Deaf Americans based on the two types of oppression of racial identity and Deaf and Hard-of-Hearing identities. ${ }^{3}$

Aramburo (1989) states that the identities of a Black Deaf person are a "double immersion" (p. 103) continually striving to overcome the communication problems faced in everyday living while still having to contend with the racist attitudes that govern society. He recognizes three issues for members of the Black Deaf American community: identity; association with the individually identified communities of Black, Deaf and Black Deaf groups; and code-switching, with sign variations among themselves and with white people.

\footnotetext{
${ }^{3}$ Since there is insufficient history documentation of Black people who are Deaf-Blind (DB) or DeafDisabled (DD), this focal group does not cover all identities in Deaf communities, such as DDBDDHH, but focuses exclusively on $\mathrm{DHH}$ people.
} 
Journal Committed to Social Change on Race and Ethnicity | Volume 6, Issue 1 | 2020

Inquiring whether a person identifies more as Black than Deaf is an outdated method. However, the following quote distinguishes between the experiences of a Black Deaf person and a white Deaf person: "You see I am black first. My deafness is not noticed until I speak or use my hands to communicate" (Aramburo, 1989, p. 110). Williamson (2007) reconfirms this position in her study of nine graduates from postsecondary institutions (p. ix). That "Black first" statement is repeated similarly in a different book with another intersecting focus, a gay identity: "Pablo" wrote anonymously, "Since my skin color is visible, they can identify me as black. Then they find out l'm Deaf. As for being gay, it's a sticky situation [because...] my rights as a gay person, they are not quite established" (Moges, 2017, p. 342 from Luczak, 1993). In a small case study, Clark (2007) interviewed three Black Deaf women, one of whom stated that she felt "more comfortable within the African American Community" than the (white) Deaf community (p. 118). When asked if they felt "support from the Deaf community to be African American," all Clark's (2006) participants responded with "a resounding "no'” (p. 119). Given our sighted society, these statements point out how identity is immediately associated with visible race before the Deaf identity and communication method are apparent.

However, racial identity should not be subsumed to a monolithic single identity of a Deaf-signing community. Aramburo (1989) states that "The majority of the respondents [...] identified themselves first with the black community. They believe that they are seen by others as black first, since unlike skin color, their deafness only becomes visible when they communicate in sign language" (p. 119). By the same token, Valli et al. (2005) evaluated 26 individuals who arrived at the same conclusion of being 
Journal Committed to Social Change on Race and Ethnicity | Volume 6, Issue 1 | 2020

identified by outsiders as Black first due to the "invisibility of deafness" (p. 251). The issue of colorism, another layer of oppression and discrimination between dark and light skin colors, has yet to be discussed in Black Deaf scholarship and remains to be explored inside Deaf communities.

"Deafness does not erase racism" (Stuart \& Gilchrist, 2005, p. 61) and, as indicated in the educational history of segregation, the Deaf community did not always provide solidarity for all Deaf people, including POC. The National Association of the Deaf (NAD) prohibited any Black person from becoming a member until 1965, during the era of the integration of schools (Dunn, 2005; McCaskill et al., 2016) based on different shades of skin color. In 1983, a century after the establishment of the NAD, National Black Advocates for the Deaf (NBDA) was founded and continues today to foster solidarity among Black Deaf people across the nation (McCaskill et al., 2016). The NBDA holds bi-annual conferences that fulfill the social, familial, and networking capital that strengthens bonds among themselves and helps to realize self-fulfillment for Black Deaf people when it is lacking in their own isolating environments due to the sparse population of Black Deaf peers. This organization provides a space for language socialization and identity formation. Almost a half-decade later after the NAD opened their membership to Black Deaf people, the organization finally issued a formal apology in 2013 to the NBDA for their past racism in preventing inclusion (Ogunyipe, n.d.).

From the work of prominent Black Deaf or signing researchers, Deaf epistemologies have gained a broad perspective of varied experiences and understandings of Deaf lives in America. This perspective has great significance and acknowledges the added layer of the racial-minority identity of POC in Deaf 
Journal Committed to Social Change on Race and Ethnicity | Volume 6, Issue 1 | 2020

communities. Instead of indulging in racial indifference, intersectionality affirms the selfvaluation of this community as an empowering Black movement in Deaf Studies, recognizing our place and our history, which can provide tools to Black Deaf studies.

\section{Ideology}

The beginning of the timeline of Deaf education in America is similar to other countries where deaf schools are founded with the objective of religious salvation by providing literacy skills to read God's word (Moges, 2015). There are significant religious roles in the spread of Deaf education, for example, Abbé Charles-Michel de l'Épée, the influential figure of signed education in France. His manual pedagogy was passed down to Laurent Clerc, who Thomas H. Gallaudet convinced to travel with him to teach white American Deaf children at the first deaf school in Hartford, Connecticut (Gannon, 1981). Eventually, Gallaudet College ${ }^{4}$ was built in Washington, D.C. History was repeated with Andrew Foster, who was the first Black Deaf graduate from Gallaudet College and who was responsible for the missionization of ASL through establishing 31 schools in West and Central Africa from 1956 to 1987 (Hairston \& Smith, 1983; Dunn, 2005). Often, these religious figures had the same drive to make education and religious texts accessible for marginalized deaf people who never had schooling opportunities. Thus, the language ideology and some language spread of hegemonic sign languages (such as ASL) that inherited European values influenced the pedagogy of manual education for religious purposes.

\footnotetext{
${ }^{4}$ Now Gallaudet “University”.
} 
Journal Committed to Social Change on Race and Ethnicity | Volume 6, Issue 1 | 2020

In 1888 , a pivotal event happened at the Milan Convention ${ }^{5}$, which determined the outcome of manual education for 80 years, affecting the quality of education that deaf schoolchildren received and led to the termination of Deaf-signing teachers, replaced with hearing non-signing teachers (Baynton, 1996; Malzkuhn, 2016). A nearly unanimous vote of 156 to 4 overturned manualism in favor of the pure oralist method of education for deaf schoolchildren across America and Europe (Baynton, 1996; Gannon, 1981). There is little information about Black deaf education due to unreported information (Settle, 1940) and few remaining historical sites of formerly Black deaf schools (Burch, 2002; Baynton, 1996). For example, in Gannon's canonical book, which contains a great deal of Deaf historical information, only three Black-segregated schools (in North Carolina, South Carolina, and Georgia) are mentioned in passing (1981).

The series of ideologies of European values perpetuating normalcy shifted from manualism through religious movements to oralism during the debate in philosophy on eugenics (Greenberg, 2007). In 1920, there were only five reported Black schools or departments in American Annals for the Deaf 65 (and the next volume, 66). Then, 20 years later, the same journal finally published scant information on surveys about Blacksegregated schools, with the statistics indicating that 11 out of $16(68.75 \%)$ schools across the nation (located in the Northeast and the South) were entirely taught using manual education, while two (12.5\%) used combined communicative teaching methods and only three (18.75\%) used oralism (Settle, 1940; Baynton, 1996).

\footnotetext{
5 "Milan Convention" refers to the historical event that took place in Milan, Italy and attracted 150+ hearing educators from Deaf institutes across the world but only one-two Deaf educators. They voted to eliminate the use of sign language in the Deaf education.
} 
Journal Committed to Social Change on Race and Ethnicity | Volume 6, Issue 1 | 2020

The history of oralism from 1890 to 1940 was not a Black Deaf experience but an element of whiteness because the oralists used the teaching method to normalize deaf schoolchildren to perform and speak like an ideal white child. Historical documentation reveals that a female African American attempted to enroll in "Normal Department" at Clarke Institution, a well-known institute for oral training located in Northampton, Massachusetts (Baynton, 1996, p. 47). The principal, who corresponded with Alexander Graham Bell ${ }^{6}$ and his wife, rejected the applicant out of fear of losing other students, because their parents would have objected (Baynton, 1996). Thus, as a form of antiblackness, the idealism of the oralist method would not be shared with alleged "savages" (as termed in Baynton, 1993, 1996) and should be known as "White Oralism," instead of generalizing the oral experiences for all Deaf Americans.

My purpose is to write this paper from the CRT perspective and to explore this quirk of fate:

Because of the continued use of sign language in the classroom, however, the ironic result of this policy of discrimination may have that southern deaf African Americans, in spite of the chronic underfunding of their schools, received a better education than most deaf White students. (Baynton, 1996, p. 180)

Other white historians have made similar statements on the history of segregation (Burch, 2002; Woodward, 1976). Black children were shunned but also saved from White Oralism due to Black hearing teachers not receiving oralism training and the lack of training programs for Black people (Burch, 2002). Often, hearing teachers, untrained in deaf education, were hired soon after graduating from the neighboring Black colleges, so the majority of them were neither supportive of nor empathetic to the betterment of

\footnotetext{
${ }^{6}$ Alexander Graham Bell was an influential figure who supported oral education and attempted to ban Deaf people from signing and exogamy to avoid maintaining their Deaf culture and population.
} 
Journal Committed to Social Change on Race and Ethnicity | Volume 6, Issue 1 | 2020

deaf education for Black Deaf children (Herring-Wright, 1999; Jowers-Barber, 2008).

Therefore, White Oralism was not enforced in Black Deaf education generally.

After the case of Miller et al. v. Board of Education of District of Columbia et al. was filed in 1952 (Jowers-Barber, 2008; McCaskill et al., 2016), deaf education was gradually desegregated, but this was not simultaneously effective throughout all schools. During the desegregation of those 17 schools in the nation, Padden and Humphries (2005) point out the significant factor that there is no record of white children moving onto any "Black campus" (p. 41). A participant in Glenn Anderson's (2006) historical collections, Lynda Carter, recalled saying to her mother: "Mama, that's not a new school, that's an old school!" (p. 36). Carter explained about feeling letdown when she initially thought that her class would be integrated to a new school but went only to her neighboring school building for white deaf children. However, there is evidence of the relocation of white deaf schoolchildren to a formerly Black institution long after desegregation era in 1975, based on a study of Georgia School for the Deaf (Knorr \& Whatley, 2015).

Nonetheless, that historical pattern is in line with Bell's (1976) interest convergence argument that the process of integration was for white people's benefit to combine educational resources in each state or county and to minimize racism to strengthen the country's image. Thus, the Black Deaf children and signing Black teachers underwent acculturation, abandoning their own familiarities of home school and language to enculturate with "Anglo ASL" (Maxwell \& Smith-Todd, 1986). Most importantly, the desegregation era took place between 1953 in the District of Columbia and 1972 in Louisiana (McCaskill et al., 2011), and it was during this period that 
Journal Committed to Social Change on Race and Ethnicity | Volume 6, Issue 1 | 2020

manualism gained in popularity once more, with a focus on signed communication and education (Lane, 2013/1984).

Researchers (i.e. Aramburo, 1989; McCaskill et al., 2011) of "Black ASL" continued to acknowledge the irony of the richness of language-access that Black students had, but such students ended up in vocational training instead of advancing their education, unlike other, white high school students. In addition, Gallaudet College did not admit Black students until 1952 (Hairston \& Smith, 1983) in the beginning of the ongoing Civil Rights movement from 1952 to 1968 . However, largely due to marginalization and the low demand for teaching qualifications to teach at Black Deaf schools, the educational curricula for Black schools were not equivalent to white schools (Baynton, 1996). Consequently, the low number and late admission of Black students to Gallaudet College during the mid-1960s resulted in the low number of Black Deaf scholars and the amount of Black Deaf scholarship to this day.

To summarize the second tenet of ideology, the paradox of disempowerment essentially nourished Black Deaf Gain. The white Eurocentric ideology impacted racial segregation and resulted in the devaluation of racial and language differences, enforcing the normativity of ideal white able-bodied religious people or eugenicists. The second tenet of Deaf LatCrit helped identify the racialized experiences through "Anglo" ASL and White Oralism, which white Deaf people's adversities were not shared with Black deaf schoolchildren. However, despite the adversity that white Deaf people endured throughout the oral era, the prosperity of Black ASL did not equate to the quality of the education of Black deaf children. Even today, Deaf culture and education are still considered to be under "apartheid" (Cohen, 1993; Simms et al., 2008) with a 
Journal Committed to Social Change on Race and Ethnicity | Volume 6, Issue 1 | 2020

short supply of Black Deaf teachers (Woodward, 1985; Simms et al., 2008). Despite the shortcomings of educational prosperity, Holcomb (2013) argues that the most significant core value of Deaf identity is communication access, which enables a person to become whole, engaging with others. This factor relates to Black schoolchildren's past experience of communicating with regional signs, which empowered them with a sense of worthiness and feeling like a whole human being.

\section{Consciousness}

Regarding the third tenet, this section discusses chronologically the linguistic studies of Black Deaf Americans that raised consciousness about their linguistic differences. A series of research papers that gradually pointed out the distinction of signs used by Black Deaf people began with the first linguistic study of ASL, and nearly each decade has followed up with new research developments. The term given to the language variation shifted over time: radical dialect difference (Croneberg, 1965), Black South Signing (Woodward, 1976), Black Signs (Aramburo, 1989), Ebonic ASL (Lewis, 2005), lexical differences (Lucas, Bayley, Reed, \& Wulf, 2001), and finally Black ASL (McCaskill et al., 2011). These linguistic researchers consistently reported that there is "a Black way of signing used by Black deaf people in their cultural milieu—among families and friends, in social gatherings, and in deaf clubs" (Harriston \& Smith, 1983, p. 55). Regarding Black Deaf scholarship, after Woodward (1976), it is important to acknowledge a great increase in the number of Deaf/Signing Black scholars studying "Black ASL," with more ontological studies.

As mentioned previously, following the surveying of the Black schooling system in American Annal in the 1940s, (Settle, 1940; Baynton, 1996), within a generation, it 
Journal Committed to Social Change on Race and Ethnicity | Volume 6, Issue 1 | 2020

was conventional for Croneberg (1965) to recognize the "radical dialect difference" ( $p$. 315) when interviewing a Black female participant from Raleigh, North Carolina. She displayed alternative signs from the ASL lexicons of the 150 other participants the researcher had surveyed, leading Croneberg (1965) to declare that, "a study of ASL dialects of the Negro deaf will constitute an important part of a full-scale sign language dialect study" (p. 315). Woodward (1976) named the linguistic difference of Black Deaf signers "Black South Signing" (p. 212) and termed it as stagnant due to the maintenance of older signs that no longer existed in standardized ASL. Woodward and DeSantis (1977) immediately followed up and claimed that African Americans use more two-handed signs than white signers.

However, Maxwell and Smith-Todd (1986) found different results, with more onehanded sign-production. While restricting their research to Austin in Texas, Maxwell and Smith-Todd (1986) suspected the one-handed signing was due to the different age group, being older than the study groups in the research paper by Woodward and DeSantis (1977). "Ebonic ASL" is produced because "while African American signers use the same lexical and syntactic structures as white signers, their signing may be said to look black or possess some characteristic Blackness" (Lewis, 2005, p. 226-7, originally published in 1998). Lucas, Bayley, Reed, and Wulf (2001) classified "lexical differences," (p. 354) with 28 out of 34 signs being produced differently by Black Deaf signers compared with white signers. Instead of a merely lexical difference, McCaskill et al. (2011) formally termed the dialect as "Black ASL" due to its differences in lexicon and its language use. 
Journal Committed to Social Change on Race and Ethnicity | Volume 6, Issue 1 | 2020

Finally, a more recent sociolinguistics study by Dr. Joseph Hill (2012), a Black ASL researcher, focused on Deaf people's attitudes and views of signing variations with three different social groups based on age, acquisition of ASL, and race (Black and white) to measure the homogeneity of the responses toward various signed fluencies. Despite the elderly Black subjects' median birth year being 1953 (later than the focal period of this history paper), only three of the 14 subjects were older Black native signers, and 11 were non-native (which Hill described as acquisition of ASL after seven years old at school). According to Hill's (2012) findings, there was a great delay for Black pupils acquiring ASL in the late 1950s and 1960s, due to their late age admissions.

Researchers of "Black ASL" have documented not only the historical signs, but also the modern signs influenced by American Black culture (McCaskill et al., 2011, 2016). Today, Black ASL remains highly visible when two fluent-signing interlocutors share similar intersectional backgrounds with Black ethnicity, Deaf identity, and the same socioeconomic class. Otherwise, their language repertoire will shift to the generic language use of ASL with other non-Black or non-Deaf-signing people. As indicated in both the historical and recent research methods, both Woodward (1976) and McCaskill et al. (2011) demonstrated the disadvantage white people had in researching, eliciting, and interviewing Black participants because they failed to recognize authentic Black ASL expressions. Therefore, the identity of this ethnic group is significant and has an enriched membership among the Black Deaf community because they shared in the same struggle in life and created a safe space for themselves. 
Journal Committed to Social Change on Race and Ethnicity | Volume 6, Issue 1 | 2020

The increasing numbers of Black Deaf scholars in linguistics and Deaf studies have researched and preserved the language that shaped the space (Black-segregated schools) and the capital of Black Deaf experience, which could be shared with similar identified group members. The chronology of linguistic findings demonstrates the epistemology of the "happy accident" in emerging Black ASL and being Black Deaf. The maintenance of Black ASL presents a distinct method of communicating and the rising prestige of the linguistic signature of this group. The act of naming this linguistic differentiation officially in the racialized title of Black ASL is a bold way of obtaining ownership of their linguistic property ${ }^{7}$. In turn, the stylistic expression of this linguistic capital is a form of Black Deaf Gain.

Eventually, to enforce social justice in the linguistic field, we need egalitarian and democratic language use (Spitulnik, 1998) between historically "higher and lower" statuses in sociolinguistics: Standard "Anglo" and Black ASL, which is discussed in the following section on counter-narratives.

\section{Counter-Narratives}

Using concrete evidence of POCs' experiential knowledge and autobiographies, this section discusses the language variation, educational oppression, and benefits of being a Black Deaf person. These counter-narratives complete the fourth tenet and serve as an act of resistance, defying racism and audism (Stapleton, 2016) and, I add, linguicism. Regarding objective, this method shifts the master-narrative that tends to read in a repetitive manner and as an essential standpoint on the unprivileged minority, such as the DPOC group. To make this research more Deaf-centric, this critical analysis

\footnotetext{
${ }^{7}$ Watch "Signing Black in America" for more stories (Cullinan \& Hutcheson, 2020).
} 
Journal Committed to Social Change on Race and Ethnicity | Volume 6, Issue 1 | 2020

adds different types of literature from not only textual published work, but also ASLnarrated anecdotes.

The work on "Black ASL" by McCaskill et al. (2011) is truly an instrumental resource, with video data on the DVD supplementary of their book, which is now online (Gallaudet University Press, n.d.). In Chapter 2 of the DVD or online video (Gallaudet University Press, 2019b), there are video clips of six Black people. Specifically, Janice Blanchard, ${ }^{8}$ the first Black Deaf person to graduate from Arkansas School for the Colored Deaf and Blind (also known as "Madison School"), presents a signed narrative that is transcribed in ASL GLOSS (documenting each sign as a word while maintaining ASL grammar):

SOME TEACHER SO-SO SIGNER. BUT ONE WHOO! ONE PERSON, WOMAN MAKE FORCE! TO CHILDREN TO MOUTH (mouthing gibberish) ORAL (Next man laughs.) HOLD-ON. NOW I-TELL STORY BRIEF. THIS TEACHER FORCE ME ORAL. (Looking dismayed). CONSTANTLY-FORCE-US SPEAK FROM BOOK SAME-SAME SPEAK (shakes head) AUDIENCE CL-absent-minded I-SPEAK (mouthing gibberish) ALL-STARING-AT-ME (Room of 6 fills with laughter.) MEGETTING-TEACHER'S-ATTENTION “THEY CANNOT HEAR (2-Handed) WHY KEEP SPEAK" "MUST LEARN ORAL" "NO, SIGN! (held up high!)" DO? SLAP TOP-OF-MY-HEAD. BOWS-HEAD. WHOA. (tried to protest) SHE KEEP ON SPEAKING (Held out open-hands) FINE. WHAT? SHE GRABBED-MY-ARM DRAG-TO PRINCIPAL (using a lexical variation in ASL). "HEY, SHE JANICE REFUSE TO LEARN TO ORAL/READ-LIP. \#SHE WANT SIGN! (Hands held up high! Then her fist bends back leaning on her hip). ("K@shoulder") PRINCIPAL "OH-I-SEE. Hmmm... HEY, LET JANICE SIGN." (Role-shifting as her teacher trying to protest) "MUST ORAL!" I LOOK UP GRIN (with a proud face and an interviewer, mostly cut off from video-frame, interrupts signing illegibly.) ME DO? RUN (moving arm/hands in a circular movement). CLAP++ NO-MORE MOUTHING!! SIGN (Hands held up very high) CLASS STUNNED! (Room filled with laughter) "Oh!! JANICE DARE!!" TWO-FIST-UP! (Another Deaf male in the room signed "TRUE, YES"). (McCaskill et al., 2011)

\footnotetext{
8 Thanks to Miki Smith for Janice's full name on her social media post when documenting about her Deaf mother, Rose Marie Smith, who was the second female graduate from Arkansas School for the Colored Deaf and Blind.
} 
Journal Committed to Social Change on Race and Ethnicity | Volume 6, Issue 1 | 2020

To summarize the English translation of the above ASL-signed narrative, the attempt by the passionate teacher to enforce the oral method was overruled and failed. Thanks to their protest, Janice and the other students were exonerated by the principal of Arkansas School, allowing them to maintain their language identity, ASL, and manualism.

The next example comes from a Black ASL researcher, Dr. Carolyn McCaskill, who experienced both segregation and desegregation in Alabama. In her signed narrative on the DVD set (McCaskill et al., 2011), now accessible online (Gallaudet University Press, 2019b), she talks about her personal journey from the Alabama Negro School for the Deaf and Blind to the integrated school:

MY EXPERIENCE PAST START BLACK DEAF INSTITUTE, I MOVE TO WHITE DEAF INSTITUTE. I THINK MY SIGNING FINE! UNTIL I ARRIVE BL-WHITE DEAF INSTITUTE, I SEE DIFFERENT SIGNING. MY TEACHER AND THOSE STUDENTS NOT UNDERSTAND MY SIGNING. THAT TEACHER SELF WHITE HEARING, POSSESSION-PARENTS DEAF, HE-ASK-ME "WHAT YOU SIGNING?" "Huh?" I-ASK TEACHER "WHAT YOU SIGNING?" I REALIZE "WhOo!" DIFFERENT OUR WAY SIGNING. I FEEL ISOLATED. I FEEL CL-uncertain. ME DROP... MY SIGNING PUT-ASIDE. (McCaskill et al. 2011; some words are italicized to display emphasis held on each word.)

In the English translation, Dr. McCaskill acculturated to the new white/"Anglo" school signs, putting aside her lexical differences that reflected her Black identity. In addition to systematic racism, she also experienced linguicism through her white teacher and classmates in their repudiation of her sign variations. Similarly, another linguistic discrimination is recorded in Maxwell and Smith-Todd's (1986) documentation, this time in an interview with a Black hearing teacher in Austin, who reported that, "teachers at 
Journal Committed to Social Change on Race and Ethnicity | Volume 6, Issue 1 | 2020

the white school did not allow the black students to use black signs after integration" ( $p$. 89).

A short video documentary captured the third signed narrative from "Johnny," whose last name is Samuels, in Florida (Young, 2020). A Deaf traveling company, "Seek the World," recorded Samuels' experience of segregation at Florida School for Deaf and Blind, which he called "Great Mother." The transcript, below, follows identically as it is captioned on the video between 0:55 and 1:59-minutes:

0:55 - Many teachers at the time had

$0: 57$ - background in oral education. They were hired $1: 02$ - in the 1930s and 1940. It was during a time there 1:05 - was heavy emphasis on oralism.

1:08 - At the Black school, I think we got the best education.

1:14 - I remember that whenever the white school got brand new

1:19 - textbooks, they would dump the older versions at the Black

1:25 - school. When it came to reading, language as well as any subject

1:33 - that demanded rigorous reading, the Black students here did

$1: 38$ - pretty well. Students here could write well and had good

1:45 - English skills. That was because we had Black Deaf teachers who

1:49 - used sign language and they were from Gallaudet University.

1:55 - At the time, this school was considered the mecca for Black

1:59 - Deaf teachers who migrated here from Gallaudet University. (2:01)

This statement is the epitome of a counter-narrative and serves as ontological evidence of a Black Deaf experience of positive gain from the exclusivity of White Oralism.

Furthermore, one autobiography presents a glimpse of what Black Deaf Gain can be. Mary Herring-Wright (1999) recalls her school years before graduating from North Carolina State School for the Deaf and Blind (Black section) in 1941. Talking about the teachers' quality of signing, she notes how one of them "seemed standoffish and cool, never bothering to really learn the signs. She mostly made up her own signs and her motions were quick and jerky. We had to teach all of the new teachers how to sign" 
Journal Committed to Social Change on Race and Ethnicity | Volume 6, Issue 1 | 2020

(Herring-Wright, 1999, p. 211). Similarly, an anecdote from Maxwell and Smith-Todd (1986) reads:

Five of the teachers stated that a few of the signs used by the students at the black school differed from the signs found in the sign language manuals and the signs these particular teachers had learned in sign language classes. They depended on their students to teach them signs more than they depended on either classes or books. (p. 89)

This story supports the knowledge of the deaf students and how the teachers were willing to accept and learn from those authentic language users. As a form of Black Deaf Gain, due to the ontology and epistemology of those Black Deaf children, Black signing teachers were able to rely on them in the perseverance of Black ASL.

Nevertheless, during Herring-Wright's invaluably filmed interview, documented on the same DVD and available online (McCaskill et al., 2011; Gallaudet University Press, 2019a), she mentions that there were three highly signing-skilled teachers at the same school. Nevertheless, she adds that there were great distinctions between white and Black signing due to her school "making up their own signs" (McCaskill et al., 2011). Therefore, from her signed comment, the regional Black signs in North Carolina were based on arbitrary signs established at her school.

One Black teacher recalled giving some white Deaf people a tour at an all-Black

Deaf school and interpreting for them but:

she was asked to stop interpreting because she could not be understood by [them]. She continued to interpret but moved to the opposite side of the [Black] audience while a white interpreter began to interpret for the white deaf visitors. (Maxwell \& Smith-Todd, 1986, p. 89)

The distinction between the sign languages was part of identity formation for Black Deaf people while maintaining (or repressing) and signifying their language property. Later in the integration of the school system, the linguicism continued: 
One teacher thought the differences in signs between generations of the black deaf are not as great now as they were one time because the older black deaf adults have 'picked up the Anglo signs' and passed them on from person to person within their generation. These 'Anglo' signs are the same signs that black deaf adolescents use today (i.e., standard ASL). (Maxwell \& Smith-Todd, 1986, p. 90)

The authors closed with the title of "standard ASL" as a commodity of white people, which may explain the language attitude (Hill, 2012) from the majority group of signers toward minority language users such as Black ASL signers. This attitude appears in one of Clark's (2007) narratives involving using "more [informal] ASL, more expressions" (bracketed by the author, p. 119). The assumption that Black ASL is "informal" but not "standard" is an act of linguicism or repression, revealing ignorance by trivializing and marginalizing the linguistic differences of Black Deaf language users.

In the history of Black Deaf manual education, we should not neglect those narratives concerning underfunded educational resources. The negative aspect of marginalization in US education is that Black Deaf students who attended segregated schools did not have many positive experiences. For her dissertation, McCaskill (2005) gathered narratives in her CRT research on Black Deaf education. One of her interview participants objected to the limited resources for the Alabama School for Negro Deaf and Blind, saying that:

actually it was not the segregation that bothered me so much as the unequal treatment that we 'minorities' had to survive. Stuff like having to do the grunt work, lousy academic programs using books and materials that had been passed down from the White schools and having inadequately trained teachers and administrative officers. (McCaskill, 2005, p. 115)

Herring-Wright (1999) shared a similar observation of class disparity between two campuses for Black Deaf and white Blind children: 
Journal Committed to Social Change on Race and Ethnicity | Volume 6, Issue 1 | 2020

we were given a tour of their campus and the differences between their school and ours were unbelievable [when] seeing such a difference in how the White children were treated and how we were treated at the Black state school left us depressed and angry. (p. 179-180)

Burch (2002) indicates that records of Black schools were not updated for many decades; whereas, white schools were well-maintained. These discouraging examples actually gained the necessary consciousness of the antiblackness they experienced through segregation and poor educational resources. Their critical consciousness is not all ornaments but had driven those Black Deaf authors with resilience to navigate through inequitable educational systems.

In sum, many examples in this section reinforce the consciousness of realizing Black ASL and the significance of having Black signing (and Deaf) models to maintain their language and resistance to assimilation and White Oralism. Janice's landmark counter-narrative indicates the resistance from the unity of Blackness to maintain what is theirs, as opposed to adopting the ideology of white able-bodied homogeneity of being able to speak and read lips. Despite many Black deaf children being suppressed in their use of Black ASL, the experience of language difference acquired a radical consciousness that formed a strong Black Deaf identity within the Deaf communities.

\section{Black Deaf Gain as a Product of the Deaf LatCrit Perspective of Deaf Education}

The irony that Black Deaf manual education flourished with communication access as opposed to white oral education is the very essence of Black Deaf Gain. One does not choose to be born Black or Deaf, but ontological study, history analysis, and experiential knowledge point toward racial and linguistic capital that granted Black Deaf immunity from attempted disempowerment by White Oralists and their ideologies. Most importantly, from the historical literature review and interpretation, Black Deaf Gain 
Journal Committed to Social Change on Race and Ethnicity | Volume 6, Issue 1 | 2020

functioned in two ways: Black Deaf-centric identity formation and the perseverance of Standard ASL through the maintenance of Black ASL. Thus, not only did Black Deaf people benefit from their racial and linguistic capital, but Black Deaf Gain contributed to the continuation of manualism for Americans in general. Using the tenets from the Deaf LatCrit framework in this paper, it is empowering to learn how Black ASL overcame hurdles and how, for children, being Black Deaf preserved their manualism.

In closing, this historical observation hopefully opens up future studies and avenues. Yet, it also does not imply a single interpretation of the documented historical phenomena and the significance of Black Deaf history. Theory is a tool that allows academia room to grow, branch out, build, and increase our understanding by considering different sides and exploring various perspectives to find deeper insights or greater truths than presently exist. The "Black Deaf Gain" concept meets the four principles of Deaf LatCrit by 1) identifying the intersectionality of antiblackness, systematic racism, linguicism, and audism that this ethnic group experience; 2) challenging with perspectives by recognizing the language and religious ideologies and empowerment that the marginalization accidentally produced; 3 ) gaining consciousness by acknowledging the great contribution of the language diversity from Black Deaf people supporting the transmission of ASL; and 4) presenting counter-narratives from Black Deaf and signing people about linguistic differentiation and repression and educational disparities. Importantly, the framework consistently honors the work of CRT and BlackCrit focusing on the intersectional experiences of Black Deaf history without 
dismissing racism or antiblackness. The concept of Black Deaf Gain ${ }^{9}$ can provide a tool that continues building a dialogue, providing a greater understanding of the world's humanity, and increasing scholarship to create a stronger foundation of Deaf POCcentralized CRT.

${ }^{9}$ Deep gratitude goes to my backers who provided some valuable textual resources that are out of print (more marginalization in effect): Earl Terry, Dr. Lina Hou, and Robert Augustus; Lex Valentine for raising the question in a social group, "Black Deaf Village", about Black oral education; Dr. Joseph Hill for the video resources and feedback; and Kari F. Cooke and my brother, Awet Moges, for greatly needed feedback. Finally, Dr. Lissa Stapleton and Dr. Carla García-Fernández for their constantly scholar support. 
Journal Committed to Social Change on Race and Ethnicity | Volume 6, Issue 1 | 2020

\section{References}

Abes, E. S., \& Wallace, M. M. (2018). "People see me, but they don't see me": Na intersectional study of college students with physical disabilities. Journal of College Student Development, 59(5), 545-562.

Ali, A. I. \& Buenavista, T. L. (Eds.). (2018). Introduction. Education at war!: The fight for students of color in America's public schools. Fordham University Press.

Anderson, G. B. (2006). Still I Rise! The enduring legacy of Black Deaf Arkansans before \& after integration. Little Rock, AR: Arkansas Association of the Deaf, Inc.

Anzaldúa, G. (1990). Haciendo Caras/making face, making soul: creative and critical perspectives by Women of Color. Aunt Lute Press.

Aramburo, A. (1989). Sociolinguistic aspect of the Black deaf community. In C. Lucas (Ed.), The sociolinguistic of the Deaf community (pp. 103-119). Academic Press.

Bauman, H-D. L., \& Murray, J. J. (2009). Reframing: From Hearing Loss to Deaf Gain. Deaf Studies Digital Journal, 1, 1-10.

Bauman, H-D. L. \& Murray, J. J. (2014). Deaf gain: Raising the stakes for human diversity. University of Minnesota Press.

Baynton, D. (1993). "Savages and Deaf-Mutes": Evolutionary theory and the campaign against sign language in the nineteenth century. In J. V. Van Cleve (ed.), Deaf history unveiled: interpretations from the new scholarship (pp. 92-112). Gallaudet University Press.

Baynton, D. (1996). Forbidden Signs: American Culture and the Campaign against sign language. University of Chicago.

Bell, Jr., D. (1976). Serving two masters: Integration ideals and client interests in school desegregation litigation. Yale Law Journal, 85(4), 470-516.

Burch, S. (2002). Signs of Resistance: American Deaf Cultural History, 1900 to 1942. New York University Press.

Clark, H. (2007). Signing and signifyin': Negotiating Deaf and African American identities. Ethnic Studies Review, 30(1\&2), 115-124.

Cohen, O. (1993). Educational needs of African American and Hispanic deaf children. In K. Christensen \& G. Delgado (Eds.), Multicultural issues in Deafness (pp. 4567). Longman.

Crenshaw, K. (1989). Demarginalizing the intersection of race and sex: A Black feminist critique of antidiscrimination doctrine, feminist theory, and antiracist politics. University of Chicago Legal Forum, 1(8), 139-167.

Crenshaw, K. (1991.) Mapping the margins: Intersectionality, identity politics, and violence against Women of Color. Stanford Law Review, 43(6), 1241-1299.

Croneberg, C. G. (1965). Sign language dialects. (Appendix) In W. C. Stokoe, D. C. Casterline, \& C. G. Croneberg, A dictionary of American Sign Language on linguistic principles (pp. 313-319). Gallaudet College Press.

Collins, P. H. (1986). Learning from the outsider within: The sociological significance of Black Feminist thought. Social Problems, 33(6), S14-S32.

Cullinan, D. \& Hutcheson, N. (2020). Signing Black in America. PBS [Video]. https://drive.google.com/file/d/1rj0B8K5kIPKKq9AppUMlknpU2_U_ccQP/view 
Journal Committed to Social Change on Race and Ethnicity | Volume 6, Issue 1 | 2020

de Clerck, G. (2010). Deaf Epistemologies as a critique and alternative to the practice of science: An anthropological perspective. American Annals of the Deaf, 154(5), $435-446$.

Delgado, R. \& Stefancic, J. (2001). Critical race theory: An introduction. New York University Press.

Dumas, M. J. \& ross, k. m. (2016). "Be real Black for me": Imagining BlackCrit in education. Urban Education, 51(4), 415-442.

Dunn, L. (2005). A dream deferred: Deaf people of African heritage and the struggle of equality and opportunity. In J. Fuller, B. Hollrah, J. G. Lewis, \& C. McCaskillHenry, (eds.), Black perspectives on the Deaf community (pp. 163-172). Gallaudet University.

Gannon, J. (1981). Deaf heritage: A narrative history of Deaf America. Silver Spring, MD: National Association of the Deaf.

Gallaudet University Press. (2019a, 17 May). Black ASL project: Mary Herring Wright's Interview. https://www.youtube.com/watch?v=6zH_zudU034

Gallaudet University Press. (2019b, 10 Feb). The Hidden treasure of Black ASL: Chapter 2. YouTube [video]. https://www.youtube.com/watch?v=OIONsvzErLk\&list=PLj06bPbAU0PqPVBXxO K2fLiond82P1Sag\&index $=3 \& t=0 \mathrm{~s}$

Gallaudet University Press. (n.d.). The Hidden Treasure of Black ASL: Companion Video to the Book. YouTube [Videos]. https://www.youtube.com/playlist?list=PLj06bPbAU0PqPVBXxOK2fLiond82P1 Sag

García-Fernández, C. (2014). Deaf-Latina/Latino critical theory in education: The lived experiences and multiple intersecting identities of deaf-Latina/o high school students. (Unpublished doctorate dissertation). University of Texas, Austin.

Gertz, E. N. (2003). Dysconscious audism and critical Deaf studies: Deaf crit's analysis of unconscious internalization of hegemony within the Deaf community. (Unpublished doctoral dissertation). University of California Los Angeles.

Greenwald, B. H. (2007). Taking stock: Alexander Graham Bell and eugenics, 18831922. In J. V. Van Cleve, The deaf history reader, (pp. 136-152). Gallaudet University Press.

Hairston, E. \& Smith, L. (1983). Black and Deaf in America. T.J. Publishers.

Herring-Wright, M. (1999). Sounds like home: Growing up Black and Deaf in the South. Gallaudet University Press.

Hill, J. C. (2012). Language Attitudes in the American Deaf Community. Gallaudet University Press.

Holcomb, T. (2013). Introduction to American Deaf culture. Oxford University Press. Humphries, T. (1977). Communicating across cultures (Deaf/hearing) and language learning. (Unpublished doctoral dissertation). Union Graduate School, Cincinnati, $\mathrm{OH}$.

Jowers-Barber, S. (2008). The Struggle to Educate Black Deaf School children in Washington, DC. In B.H. Greenwald \& J. V. Van Cleve (eds.), A Fair Chance in the Race of Life: The Role of Gallaudet University in Deaf History (pp. 113-132). Gallaudet University Press. 
Journal Committed to Social Change on Race and Ethnicity | Volume 6, Issue 1 | 2020

Knorr, R. \& Whatley, C. (2015). The segregated Georgia School for the Deaf: 18821975. Sunbury Press.

Kusters, A., M. De Meulder \& D. O'Brien. (2017). Innovations of Deaf scholars. Oxford University Press.

Lane, H. (2013 [1984]). When the mind hears: A history of the Deaf. Vintage Books.

Lewis, J. G. (2005). Ebonics in American sign language: Stylistic variation in African American signers. In J. Fuller, B. Hollrah, J. G. Lewis, \& C. McCaskill-Henry (eds.), Black perspectives on the Deaf community (pp. 221-235). Gallaudet University Press.

Lucas, C., Bayley, R., Reed, R., \& Wulf, A. (2001). Lexical variation in African American and White signing. American Speech, 76(4), 339-360.

Luczak, R. (1993). Eyes of desire: A Deaf gay and lesbian reader. Alyson Publications.

Malzkuhn, M. (2016). Compromising for agency: The role of the NAD during the American eugenics movement, 1880-1940. In B. H. Greenwald \& J. J. Murrayeds (eds), In our own hands: Essays in Deaf history, 1780-1970, (pp. 171-193). Gallaudet University Press.

Maxwell, M. M. \& Smith-Todd, S. (1986). Black sign language and school integration in Texas. Language in Society, 15(1), 81-93.

McCaskill, C. (2005). The education of Black Deaf Americans in the 20th century: Policy Implications for administrators in residential schools for the Deaf. (Unpublished doctoral dissertation). Gallaudet University.

McCaskill, C., Lucas, C., Bayley, R., \& Hill, J. (2011). The hidden treasure of Black ASL: Its history and structures. Gallaudet University Press.

McCaskill, C., Lucas, C., Bayley, R., \& Hill, J. (2016). Citizenship and education: The case of Black Deaf community. In B. H. Greenwald \& J. J. Murrayeds (eds), In our own hands: Essays in Deaf history, 1780-1970, (pp. 40-60). Gallaudet University Press.

Moges, R. (2015). Resistance is NOT futile: Language planning and demissionization of Eritrean sign language. In K.K. Rashid \& A.A. Cooper (eds.), Citizenship, politics, difference: Perspectives from sub-Saharan signed language communities (pp. 64-80). Gallaudet University Press.

Moges, R. (2017). Cripping Deaf studies and Deaf literature: Deaf Queer ontologies and intersectionality. In A. Kusters, M. De Meulder \& D. O'Brien (eds.), Innovations of Deaf scholars (pp. 330-364). Oxford University Press.

Padden, C. A. \& Humphries. T. L. (2005). Inside Deaf culture. Harvard University Press.

Ogunyipe, B. (n.d.). Black Deaf Culture Through the Lens of Black Deaf History. https://dcmp.org/learn/366-black-deaf-culture-through-the-lens-of-black-deafhistory

Parasnis, I. (2012). Diversity and Deaf identity: Implications for personal epistemologies in Deaf education. In P. Paul \& D. Moores (eds.), Deaf epistemologies: Multiple perspectives on the acquisition of knowledge (pp. 63-80). Gallaudet University Press.

Settle, C. (1940). Normal training for colored teachers. American Annals of the Deaf, $85,209-215$. 
Journal Committed to Social Change on Race and Ethnicity | Volume 6, Issue 1 | 2020

Simms, L., Rusher, M., Andrews, J. F., \& Coryell, J. (2008). Apartheid in Deaf education: Examining workforce diversity. American Annals of the Deaf, 153(4), 384-395.

Skutnabb-Kangas, T. (1988). Multilingualism and the education of minority children. In T. Skutnabb-Kangas \& J. Cummins (Eds.), Minority education: From shame to struggle, (9-44). Multilingual Matters.

Spitulnik, D. (1998). Mediating unity and diversity: The production of language ideologies in Zambian broadcasting. In B. Schieffelin, K. Woolard \& P. Kroskrity (Eds.), Language ideologies: Practice and theory (pp. 163-188). Oxford University Press.

Solórzano, D. (1997). Images and words that wound: Critical race theory, racial stereotyping and teacher education. Teacher Education Quarterly, 24, 5-19.

Solórzano, D. G. \& T. J. Yosso. (2002). Critical race methodology: Counter-storytelling as an analytical framework for education research. Qualitative Inquiry, 8(1), 2344.

Stapleton, L. D. (2014). The unexpected talented tenth: Black d/Deaf students thriving within the margins. Unpublished PhD Dissertation. lowa State University.

Stapleton, L. D. (2016). Audism and racism: The hidden curriculum impacting Black d/Deaf college students in the classroom. The Negro Educational Review, 67(14), 150-168.

Stapleton, L. D., \& Croom, N. (2017). Narratives of Black d/Deaf college alum: Reflecting on intersecting microaggressions in college. Journal of Student Affairs Research and Practice, 54(1), 15-27.

Stuart, P. \& Gilchrist, A. (2005). A Sense of Identity. In J. Fuller, B. Hollrah, J. G. Lewis, \& C. McCaskill-Henry (Eds.), Black perspectives on the Deaf community (pp. 6171). Gallaudet University.

Valli, C., Reed, R., Ingram, N. \& Lucas, C. (2005). Sociolinguistic issues in the Black Deaf community. In J. Fuller, B. Hollrah, J. G. Lewis, \& C. McCaskill-Henry (Eds.), Black perspectives on the Deaf community (pp. 237-255). Gallaudet University.

Williamson, C. M. (2007). Black Deaf students: A model for educational success. Gallaudet University Press.

Woodward, J. C. (1976). Black Southern Signing. Language in Society 5(2), 211-218.

Woodward, J. C. (1985). Black Deaf teacher-Short supply. Perspectives for Teachers of the Hearing Impaired, 4, 18-19.

Woodward, J. C., \& DeSantis, S. (1977). Two to one it happens: Dynamic phonology in two sign languages. Sign Language Studies, 17, 329-346.

Young, C. (2020, March 18). The powerful history story about Deaf Black \& White students separated [Video]. https://youtu.be/5WI7kwG9tGY 